\title{
Networking
}

\section{Research in cardiovascular disease: meeting the challenges of the National Service Framework}

The UK Federation of Primary Care Research Networks decided to hold a series of workshops on meeting the challenges of the National Service Frameworks (NSFs).

The first of these was hosted by NoReN, the Northern Primary Care Research Network, and was held in Durham on 23 June 2000.

The Director of NoReN, Professor Pali Hungin, has sent the following report on what emerged from the day.

The NSFs being released by the Department of Health are essentially service orientated. However, they point to many research opportunities, not least the evaluation of new services and measurement of the clinical outcomes of specific interventions. Importantly, they highlight health areas which are of national importance and likely to attract research funding.

\section{A Federation Workshop in Durham}

NoReN hosted a national meeting on coronary heart disease in Durham on behalf of the National Federation in June this year. The aim was to enable researchers involved in cardiovascular research from networks all over the UK to present work in progress, to share experiences and to develop internetwork proposals. A total of 26 people with different health backgrounds from several networks (including the MRC) attended. Professor Stephen Ball, Cardiologist, Leeds University and Professor Richard Thompson, Department of Epidemiology and Public Health, Newcastle University, also resourced the day.

The themes which emerged centred on heart failure, atrial fibrillation and anticoagulation, patient attitudes and the ease of access to information for patients. The meeting also recognized the human element of interventions in cardiovascular disease. These are often complex and involve poly(C)Arnold 2001 pharmacy in what is essentially an aged population, as well as the effects of intrusive interventions in an otherwise well group (e.g., those on anticoagulants).

\section{Need for greater collaboration ... rethinking methodologies}

The workshop highlighted a number of infrastructure problems. There is a need for greater collaboration between primary and secondary care researchers. These partnerships are proving difficult to forge, especially beyond the immediate localities. There is also a major question mark over the appropriateness and expediency of randomized controlled trials (RCTs) for the evaluation of service interventions, particularly in such a fast-moving field.

\section{Don't forget the public health people ...}

Perhaps the most important message from the day was recognition of the role of public health professionals in this field. They constitute an important resource for planning and methodological support. As they are directly concerned with prevention and the evaluation of interventions for improving health on the larger scale, they are natural partners for many primary care research initiatives. They are also more likely to be accessible than the average cardiologist! Networks should look closely at means of forging closer links with public health and, if possible, with academic departments.

\section{Was the workshop worthwhile?}

The answer is yes! Tangible outputs included the discovery of new research partners as well as new 1463-4236(2001)PC040XX 


\section{Pali Hungin}

research ideas, and a decision to approach the MRC with a view to facilitating greater interdisciplinary contact at a national level. It seems that researchers in this field feel a high degree of isolation at present. A follow-up workshop on coronary heart disease is likely to be held, and we in NoReN feel that this is a good way to engage networkers with the possibilities of research alongside the NSFs.
Professor Pali Hungin Director of NoReN

\section{Networking page submissions}

If you are part of a Primary Health Care Research Network, or if you would like to comment on such networks, you are encouraged to submit a commentary of up to 300-400 words to Muriel Lee at the address below. Longer pieces may also be considered in consultation with the co-ordinator.

Muriel Lee, ResNET Co-ordinator

Centre for Research in Primary Health Care

Buckinghamshire Chilterns University College

Gorelands Lane

Chalfont St Giles

Buckinghamshire

HP8 4AD

E-mail: muriel.lee@ bcuc.ac.uk

Tel: 01494522141 ext. 2283

Subject to Editorial review 